\title{
CORRECTION
}

\section{Correction to: Management of symptomatic knee osteoarthritis in obesity: a survey of orthopaedic surgeons' opinions and practice}

\author{
Daniel S. Hill ${ }^{1}$ Matthew Freudmann ${ }^{2} \cdot$ Jamie C. Sergeant ${ }^{3,4} \cdot$ Tim Board $^{1}$
}

Published online: 8 May 2018

๑) Springer-Verlag France SAS, part of Springer Nature 2018

\section{Correction to: \\ European Journal of Orthopaedic Surgery \& Traumatology \\ https://doi.org/10.1007/s00590-017-2103-9}

The corresponding author would like to state a different e-mail address: drdanielhill@icloud.com.

The original article can be found online at https://doi.org/10.1007/ s00590-017-2103-9.

Daniel S. Hill

drdanielhill@icloud.com

1 Wrightington Lower Limb Unit, Wrightington Hospital, Appley Bridge, Wigan, Lancashire WN6 9EP, UK

2 Department of Orthopaedic Surgery, Furness General Hospital, Barrow in Furness, Cumbria LA14 1GP, UK

3 Centre for Biostatistics, Manchester Academic Health Science Centre, University of Manchester, Manchester, UK

4 Arthritis Research UK, Centre for Epidemiology, Centre for Musculoskeletal Research, Manchester Academic Health Science Centre, University of Manchester, Manchester, UK 